\title{
KAJIAN GEOMORFOLOGI KOMPLEKS GUA SEPLAWAN KAWASAN KARST JONGGRANGAN
}

\author{
Oleh: \\ Arif Ashari \\ Jurusan Pendidikan Geografi FIS UNY \\ ariecarstensz@gmail.com
}

\begin{abstract}
Abstrak
Penelitian ini bertujuan untuk mengkaji geomorfologi Gua Seplawan pada kawasan Karst Jonggrangan yang meliputi: (1) tipe gua dan bentuklahan di sekitar gua, (2) tipe lorong gua, dan (3) keberadaan speleothem dan speleogen dalam gua. Kajian geomorfologi gua merupakan informasi yang bermanfaat untuk menunjukkan rekam jejak perkembangan karst serta sebagai arahan pengembangan pariwisata penelusuran gua. Metode yang digunakan adalah survei geomorfologi dengan memperhatikan aspek morfologi dan morfogenesa. Pengumpulan data dilakukan dengan observasi, dokumentasi, dan studi pustaka. Analisis data dengan analisis morfologi dan keruangan secara deskriptif. Hasil penelitian menunjukkan gua seplawan termasuk dalam kategori pit cave, yang terbentuk oleh karena pelebaran lubang ponor pada dasar doline. Lorong dalam gua memiliki bentuk bervariasi, antara lain berupa eliptical passage, rectangular passage, canyon, dan joint passage. Speleothem berupa stalaktit, stalagmit, dan drappery dijumpai pada wilayah dekat mulut gua. Adapun speleogen berupa solution notch, solution pocket, pothole, scallop, dan karren anastomoses dijumpai di seluruh wilayah gua.
\end{abstract}

Kata kunci: geomorfologi karst, gua karst, speleothem, speleogen

\section{A STUDY ON GEOMORPHOLOGY OF SEPLAWAN CAVE COMPLEX IN KARST REGION JONGGRANGAN}

\begin{abstract}
This research aims to study the geomorphology of Seplawan cave in Karst region Jonggrangan. This includes: (1) the type of cave and landform around the cave, (2) the type of cave tunnel, and (3) the existence of speleothem and speleogen in the cave. The geomorphologic study of caves provides useful information to demonstrate a track record of karst development as well as to guide the development of cave tourism. The method employed in this research is a geomorphologic survey by focusing on morphology and morfogenesa. The data was collected through observation, documentation, and literary study. The data analysis was performed using descriptive-morphologic and spatial analysis. The findings show that seplawan cave belongs to the category of pit cave, formed by the widening of the ponor hole in the doline base. The tunnel in the cave have different forms namely, passage eliptical, rectangular passage, canyon, and joint passage. Speleothem in the form of stalactites, stalagmites, and drappery is found near the mouth of the cave. Moreover, the speleogen in the form of a notch solution, solution pocket, pothole, scallops, and Karren anastomoses is found in all parts of the cave.
\end{abstract}

Keywords: karst geomorphology, karst caves, speleothem, speleogen 


\section{Pendahuluan}

Kesempurnaan proses karstifikasi dalam perkembangan bentuklahan karst antara lain dicirikan oleh morfologi yang dihasilkan. Keberadaan sistem endokarst berupa guagua beserta ornamen di dalamnya menandakan suatu kawasan karst telah berkembang lanjut oleh karena proses karstifikasi yang berlangsung secara intensif. Tingkat perkembangan karst erat kaitannya dengan keberadaan berbagai potensi yang dapat dikelola, namun disisi lain juga mengindikasikan kerentanan terhadap kerusakan lingkungan. Oleh karena itu agar pengelolaan kawasan karst dapat dilakukan secara optimum dan menghindarkan kesalahan pengelolaan, kajian mengenai tingkat perkembangan karst dengan memperhatikan aspek geomorfologi dan hidrologi karst sangat penting untuk dilakukan. Salah satu pendekatan yang dapat digunakan untuk mengidentifikasi tingkat perkembangan karst adalah kajian dan pemetaan mengenai kondisi geomorfologi endokarst pada gua-gua karst.

Menurut Palmer (1991) kajian mengenai gua karst perlu dilakukan berkaitan dengan berbagai kepentingan antara lain interpretasi kondisi hidrologi dan geomorfik, estimasi potensi akuifer, pergerakan kontaminan air, serta stabilitas tanah dan batuan dasar. Di Indonesia, khususnya di Pulau Jawa, kajian sistem gua karst telah dilakukan dalam berbagai aspek dan tujuan antara lain untuk: analisis hidrogeokimia airtanah pasca proses karstifikasi di Karst Gunungsewu (Adji, 2010), identifikasi potensi sumberdaya yang dapat dikelola di Karst Kendeng (Wacana dkk, 2010), fungsinya bagi habitat fauna gua (Rahmadi, 2010), serta aspek-aspek lainnya. Penelitian ini lebih khusus bertujuan untuk mengidentifikasi dan memetakan bentukan-bentukan endokarst sebagai hasil proses geomorfologi serta dalam terapan untuk mendukung pengembangan pariwisata gua. Bentukan endokarst dalam gua meliputi tipe gua, pola lorong gua, serta keberadaan speleogen dan speleothem dalam gua.

Gua Seplawan merupakan salah satu gua karst yang berkembang di wilayah Karst Jonggrangan. Saat ini Gua Seplawan telah dikelola sebagai tujuan wisata penelusuran gua di Kabupaten Purworejo. Dari segi pelayanan wisata, pengelolaan yang telah dilakukan tergolong cukup baik. Namun demikian atraksi yang ditawarkan masih terbatas pada sisi estetik dan belum memperhatikan aspek keilmuan. Dalam pengelolaan dan pengembangan obyek wisata gua perlu diperhatikan faktor kelestarian dan pengamanan gua beserta ekosistem di dalamnya (Worosuprojo, 1996), dimana ekosistem dalam gua sangat rentan terhadap kerusakan terutama oleh karena pengaruh manusia (Wynne dan Pleytez, 2005). Untuk itu selain aspek estetik seyogyanya aspek keilmuan juga ditingkatkan sehingga wisatawan selain dapat menikmati keindahan gua juga memahami berbagai fenomena yang dijumpai. Identifikasi dan pemetaan morfologi gua merupakan referensi bagi pengembangan aspek kelimuan dalam pengelolaan pariwisata di Gua Seplawan. Melalui penanaman aspek keilmuan, diharapkan wisatawan dapat diajak untuk menjaga kelestarian gua sehingga manfaat yang diperoleh melalui pengembangan wisata dapat dirasakan secara berkelanjutan. 


\section{Metode Penelitian}

Penelitian ini menggunakan metode eksploratif-survei dengan pendekatan keruangan. Survei geomorfologi digunakan dengan memperhatikan aspek morfologi dan morfogenesa. Pengumpulan data dilakukan dengan cara observasi, interpretasi citra penginderaan jauh, studi pustaka, dan dokumentasi. Data yang dikumpulkan meliputi data primer dan data sekunder. Data primer berupa hasil pengukuran dan pengamatan lapangan mengenai morfologi Gua Seplawan yang meliputi: (1) jarak, kemiringan, lebar, dan tinggi atap lorong gua, (2) speleogen, dan (3) speleothem. Data sekunder meliputi: (1) kondisi geologi dan geomorfologi wilayah sekitar gua seplawan yang diperoleh dari peta geologi, peta rupabumi indonesia, serta interpretasi citra ikonos yang tersedia pada google earth, (2) informasi geomorfologi regional yang diperoleh dari sumber pustaka. Jenis data dan metode pengumpulannya ditunjukkan pada Tabel 1 .

Tabel 1. Jenis data dan teknik pengumpulan data

\begin{tabular}{|l|l|l|}
\hline Jenis data & $\begin{array}{l}\text { Teknik } \\
\text { pengumpulan data }\end{array}$ & Instrumen/sumber data \\
\hline Variabel tipe lorong gua: & & \\
\hline 1. Panjang dan arah lorong & Observasi & kompas, roll meter, yallon \\
\hline 2. Lebar lorong & Observasi & kompas, roll meter, yallon \\
\hline 3. Tinggi atap & Observasi & kompas, roll meter, yallon \\
\hline 4. Kemiringan dasar lorong & Observasi & Kompas, klinometer, yallon \\
\hline Variabel jenis speleogen & Observasi & Lembar observasi \\
\hline Variabel jenis speleothem & Observasi pustaka, & Lembar observasi \\
\hline $\begin{array}{l}\text { Variabel kondisi geologi dan } \\
\text { geomorfologi regional }\end{array}$ & $\begin{array}{l}\text { Studi Bemmeen (1949), } \\
\text { dokumentasi, } \\
\text { interpretasi citra }\end{array}$ & $\begin{array}{l}\text { Pannekoek (1949), citra ikonos } \\
\text { 2006 pada google earth }\end{array}$ \\
\hline
\end{tabular}

Data yang diperoleh selanjutnya dianalisis dengan menggunakan kombinasi antara analisis geomorfologi dengan analisis deskriptif. Analisis geomorfologi digunakan untuk mengidentifikasi tipe lorong gua berdasarkan hasil pengukuran lapangan, serta mengenali berbagai jenis speleogen dan speleothem yang dijumpai berkaitan dengan proses pembentukannya. Dalam konteks ini, analisis geomorfologi memperhatikan dua aspek yaitu aspek morfologi dalam hal mengenali bentuk yang dijumpai, serta aspek morfogenesa dalam hal pendugaan proses yang telah bekerja sehingga menghasikan bentuk tersebut. Selanjutnya penentuan tipe lorong gua dari data hasil pengukuran lapangan dilakukan dengan menggunakan perangkat lunak survex, dengan luaran berupa peta pola lorong gua beserta kenampakan speleogen dan speleothem di dalamnya. Adapun analisis deskriptif digunakan untuk memperjelas pembahasan dari informasi yang dihasilkan pada analisis geomorfologi.

\section{Hasil Penelitian}


Gua Seplawan merupakan salah satu gua yang berkembang di kawasan Karst Jonggrangan. Pintu masuk ke kawasan gua ini terletak pada koordinat 401801 MT dan 9140738 MU zona 49 UTM. Secara administrasi Gua Seplawan berada di wilayah Desa Donorejo, Kecamatan Kaligesing, Kabupaten Purworejo. Karst Jonggrangan sendiri merupakan kawasan karst yang berkembang di Pegunungan Kulon Progo, teretak pada 399892 MT hingga 406053 MT serta 9139671 MU hingga 9147783 MU dengan luas wilayah $25 \mathrm{~km}^{2}$. Karst Jonggrangan terletak pada perbatasan Kabupaten Kulon Progo dan Kabupaten Purworejo. Secara administrasi Kabupaten Kulon Progo meliputi Desa Purwosari dan Jatimulyo, Kecamatan Girimulyo sedangkan Kabupaten Purworejo meliputi

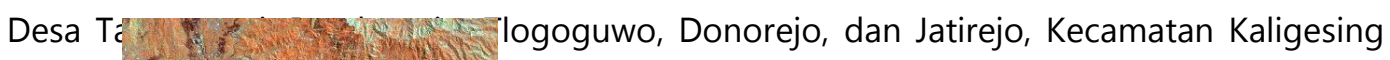

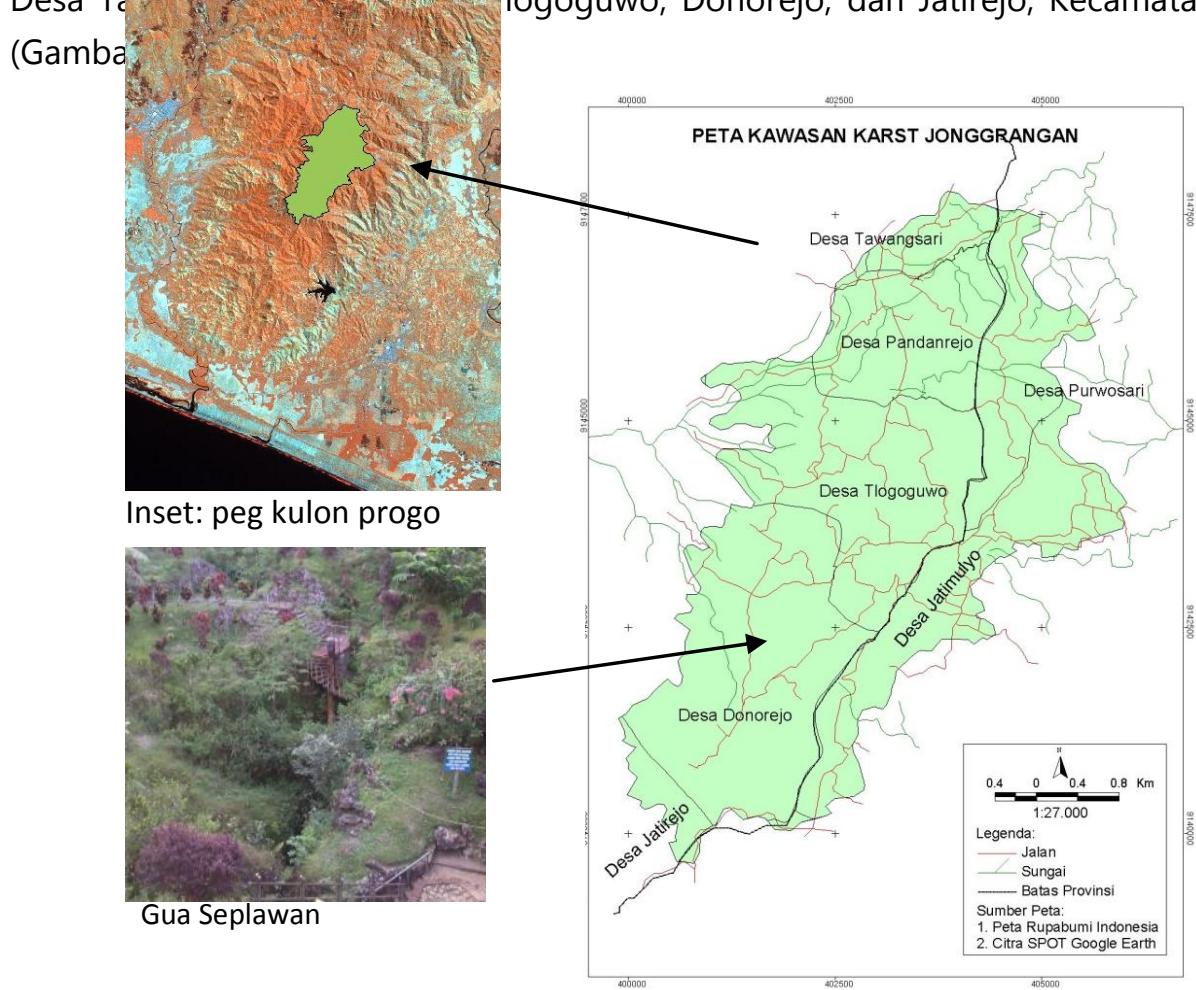

Gambar 1. Daerah Penelitian

Karst Jonggrangan berkembang pada Formasi Jonggrangan dengan litologi konglomerat, napal tufan, dan batugamping pasiran dengan sisipan lignit batugamping berlapis dan koral, berusia Miosen Bawah. Formasi di bagian bawah Karst Jonggrangan adalah batuan andesit tua dari tiga gunungapi menurut Van Bemmelen (1949), atau Formasi Kebobutak menurut peta geologi Yogyakarta tahun 1995. Kondisi hidrologi pada bagian lereng pegunungan ditandai keberadaan sistem sungai yang merupakan bagian DAS Bogowonto dan DAS Progo, sedangkan pada bagian tengah Karst Jonggrangan didominasi pola aliran multi basinal. Ketinggian tempat mencapai 800-900 mdpal sehingga hujan cukup banyak terjadi dan mempengaruhi kondisi iklim bersifat basah. Penggunaan lahan di Karst Jonggrangan umumnya berupa kebun campuran. 
Secara geomorfologi, wilayah Karst Jonggrangan dapat dibedakan menjadi dua bagian yaitu Plato Jonggrangan di bagian tengah dengan karakteristik holokarst dan sayap lereng pegunungan di bagian tepi dengan karakteristik fluviokarst. Plato Jonggrangan memiliki bukit-bukit karst tipe menara dengan dolin berupa cekungancekungan tertutup berbentuk oval atau lonjong, sedangkan sayap lereng pegunungan memiliki lembah-lembah terbuka yang mencirikan tahap awal perkembangan karst (Pench, 1904; Sawicki, 1909; Cvijic, 1918; dan Dicken, 1935; dalam Haryono, 2008). Lembah-lembah tersebut berhubungan dengan sistem aliran sungai di luar kawasan karst sebagai bagian DAS Progo di bagian timur dan DAS Bogowonto di bagian barat. Proses karstifikasi di bagian Plato Jonggrangan didominasi oleh proses solusional sedangkan pada sayap lereng pegunungan juga berlangsung proses fluvial.

Gua Seplawan berkembang pada cekungan tertutup yang dibatasi oleh bukit-bukit karst. Pintu masuk gua (mulut gua/entrance) berada pada dasar cekungan dengan posisi vertikal, sehingga diduga Gua Seplawan berkembang pada pelebaran lubang ponor suatu dolin yang berhubungan dengan lorong bawah permukaan. Berdasarkan kedudukan pintu masuknya, Gua Seplawan merupakan contoh tipe gua vadose. Gua vadose sering disebut juga pit caves, yang merupakan suatu jalur hasil proses pelarutan akibat tenaga air yang turun ke bawah permukaan secara vertikal menuju water table. Pit caves dikenal pula dengan istilah vadose shaft yang memiliki ciri utama berbentuk vertikal, atau membentuk pola bertingkat pada dinding (Myloire dan Carew, 1995). Pit caves umumnya terbentuk di zona epikarst, namun di Gua Seplawan dijumpai pada pelebaran ponor yang didorong oleh adanya pola kekar batugamping (Gambar 2). Mulut gua vertikal menghubungkan permukaan lahan dengan dasar gua pada kedalaman 5-6 meter, dari titik pertama pada dasar gua ini lorong gua seplawan berlanjut mendatar ke arah $\mathrm{N} \mathrm{200^{ \circ }}$ E.

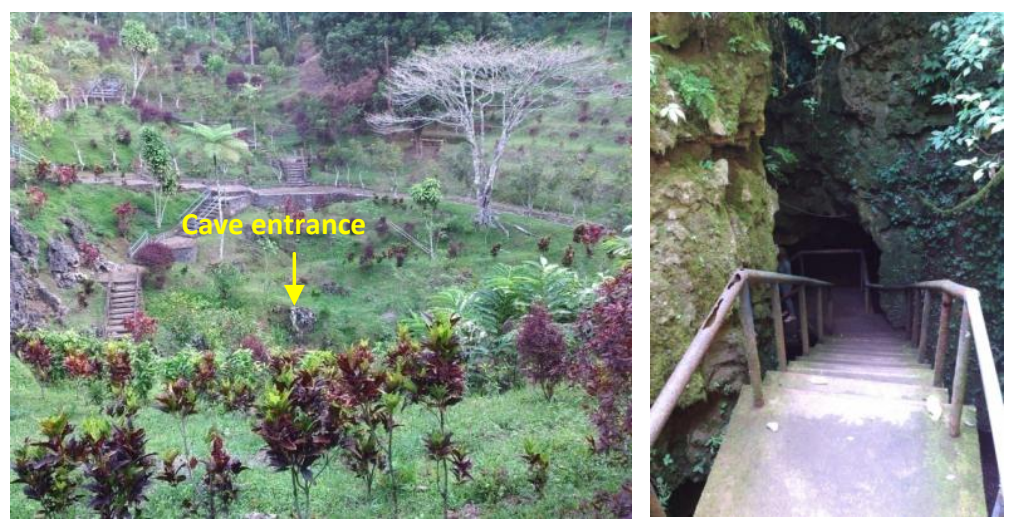

Gambar 2. Lingkungan sekitar Gua Seplawan berupa cekungan tertutup (gambar kiri), pintu masuk gua berupa pit cave vertikal yang telah dibangun tangga permanen (gambar kanan)

Lorong gua seplawan yang diidentifikasi dalam penelitian ini memiliki panjang total 749,50 meter, yaitu lorong gua yang saat ini telah dikelola sebagai obyek wisata. Lorong gua ini berakhir pada lubang menyempit ke arah bawah dari lantai gua yang belum pernah dieksplorasi. Gua Seplawan memiliki tipe lorong yang sangat bervariasi. Pada awal 
penelusuran dijumpai tipe eliptical passage dengan lebar lorong 7,5 meter dan tinggi atap 3 meter. Speleogen berupa solution notch dan speleothem berupa kumpulan stalaktit pada atap gua. Selanjutnya dijumpai joint passage berbentuk tinggi dan sempit dengan lebar lorong $7-10$ meter dan tinggi atap $10-15$ meter. Speleogen berupa solution notch, solution pocket, dan scallops, sedangkan speleothem berupa drappery dan stalagmit. Pada jarak 40 meter dari pintu masuk gua dijumpai deretan sarang kelelawar yang telah ditinggalkan, diduga oleh karena pengaruh penerangan lampu yang dipasang dalam gua.

Pada jarak 100 meter dari pintu masuk gua dijumpai tipe lorong gorge shaped passage atau initial canyon. Solution notch dan solution pocket masih dijumpai pada dasar dinding gua berkombinasi dengan stalaktit pada atap gua. Selanjutnya tipe lorong berubah menjadi rectangular passage hingga jarak 35 meter, lalu kembali initial canyon dan canyon sempurna. Pada tipe lorong rectangular passage, solution notch masih dijumpai bersama-sama dengan solution pocket, namun pada tipe lorong canyon hanya dijumpai solution notch. Speleothem pada lorong rectangular passage berupa stalaktit dan flowstone, sedangkan pada canyon hanya dijumpai drappery. Pada lokasi ini di beberapa titik kembali dijumpai sarang kelelawar yang telah ditinggalkan. Selain itu pada aliran di dasar gua juga terdapat spesies udang berukuran kecil. Pada 72 meter terakhir hingga batas penelusuran dijumpai tipe lorong joint passage dengan bentuk sangat rapi dan tanpa runtuhan. Erosi oleh aliran masih terjadi pada dasar saluran membentuk solution notch disertai pengendapan sedimen klastik sepanjang aliran. Ukuran lorong sangat besar dengan lebar 10 hingga 15 meter dan atap gua diperkirakan 30 hingga 50 meter. Speleothem pada dinding gua hanya berupa drappery.

Berdasarkan hasil pengamatan dan pengukuran morfologi gua diketahui Gua Seplawan memiliki lorong tunggal, terhubung dengan beberapa lorong kecil (conduit) yang tidak dapat dilalui untuk penelusuran dan hanya berfungsi sebagai bagian sistem aliran. Rangkuman hasil pengamatan dan pengukuran ditunjukkan Tabel 2, visualisasi morfologi yang teridentifikasi ditunjukkan Gambar 3, dan peta lorong gua ditunjukkan Gambar 4.

Tabel 2. Rangkuman hasil pengukuran morfologi Gua Seplawan

\begin{tabular}{|c|c|c|c|c|c|c|c|c|c|}
\hline \multicolumn{2}{|c|}{$\begin{array}{c}\text { Titik } \\
\text { (dari-ke) }\end{array}$} & $\begin{array}{c}\text { Jarak } \\
\text { (m) }\end{array}$ & $\begin{array}{c}\text { Arah } \\
\text { ( } N \text { to } E)\end{array}$ & $\begin{array}{c}\text { Lereng } \\
\text { (\%) }\end{array}$ & $\begin{array}{l}\text { Tinggi } \\
\text { atap }(\mathrm{m})\end{array}$ & $\begin{array}{l}\text { Lebar } \\
\text { (m) }\end{array}$ & $\begin{array}{c}\text { Tipe lorong } \\
\text { (passage) }\end{array}$ & $\begin{array}{l}\text { Speleo } \\
\text { gen }\end{array}$ & $\begin{array}{c}\text { Speleo } \\
\text { them }\end{array}$ \\
\hline 0 & 1 & \multicolumn{8}{|c|}{ Vertikal (pit cave) } \\
\hline 1 & 2 & 4 & 200 & -22 & 3 & 7,5 & Eliptical & 1 & A \\
\hline 2 & 3 & 17 & 125 & -5 & 10 & 7 & Joint & 2,3 & $A, B, C$ \\
\hline 3 & 4 & 19 & 210 & -6 & 15 & 10 & Joint & 2,4 & $A, B, C$ \\
\hline 4 & 5 & 10 & 190 & -10 & 2,5 & 4,5 & Eliptical & 2 & $A, C$ \\
\hline 5 & 6 & 5 & 170 & 0 & 5 & 5 & Gorge shaped & 1,2 & A \\
\hline 6 & 7 & 2 & 210 & 75 & 1,5 & 1 & Rectangular & 1,2 & $A$ \\
\hline 7 & 8 & 6 & 140 & 15 & 4 & 3 & Rectangular & 1,2 & $A, D$ \\
\hline 8 & 9 & 12 & 250 & 3 & 6 & 6 & Rectangular & $1,2,4$ & A \\
\hline 9 & 10 & 10 & 190 & -3 & 6 & 6 & Rectangular & 1 & $\mathrm{~A}$ \\
\hline 10 & 11 & 13 & 180 & -10 & 10 & 6 & Gorge shaped & 1 & - \\
\hline 11 & 12 & 11 & 220 & 0 & 20 & 5 & Canyon & 1 & $\mathrm{C}$ \\
\hline 12 & 13 & 10 & 270 & 0 & 20 & 5 & Canyon & 1 & - \\
\hline
\end{tabular}




\begin{tabular}{|r|r|r|r|r|r|r|l|c|c|}
\hline 13 & 14 & 10 & 300 & 0 & 20 & 8 & Canyon & 1 & C \\
\hline 14 & 15 & 27 & 270 & 6 & 12 & 4 & Canyon & 1 & - \\
\hline 15 & 16 & 39 & 210 & 32 & 50 & 10 & Eliptical & 1,2 & - \\
\hline 16 & 17 & 26 & 160 & 0 & 50 & 10 & Gorge shaped & 1 & $\mathrm{C}$ \\
\hline 17 & 18 & 30 & 260 & 35 & 30 & 5,5 & Joint & 1 & - \\
\hline 18 & 19 & 12 & 180 & 0 & 5 & 15 & Joint & 1 & - \\
\hline 19 & 20 & 30 & 270 & 20 & 50 & 10 & Joint & 1 & C \\
\hline
\end{tabular}

Speleogen $=1$ solution notch, 2 soution pocket, 3 pothole, 4 scallop Speleothem $=$ A stalaktit, $\mathrm{B}$ stalagmit, $\mathrm{C}$ drappery, $\mathrm{D}$ flowstone
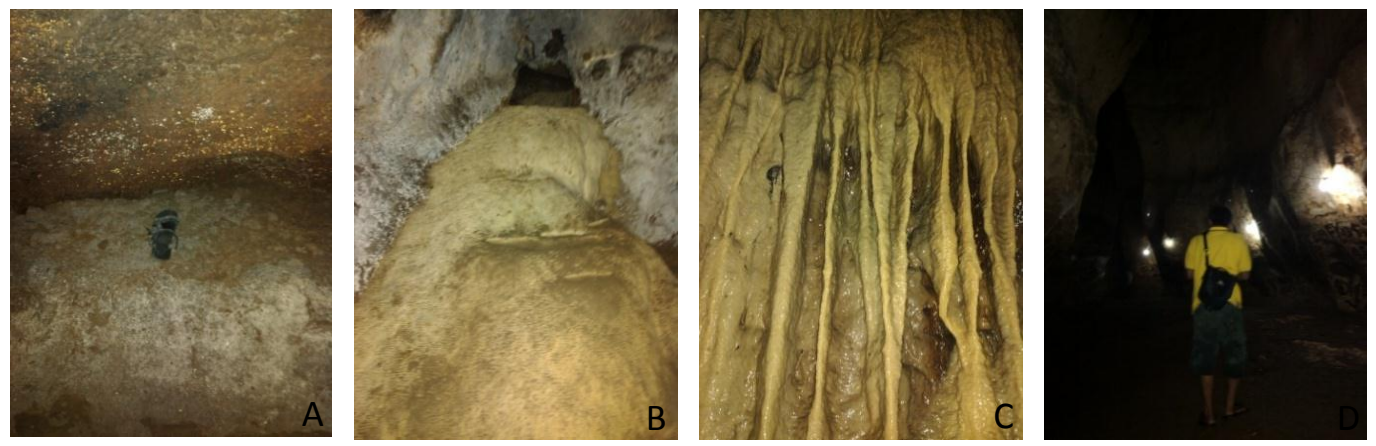

Gambar 3. Kenampakan dalam Gua Seplawan: A. solution notch, B. flowstone, C. drapperies, D. tipe lorong joint passage 


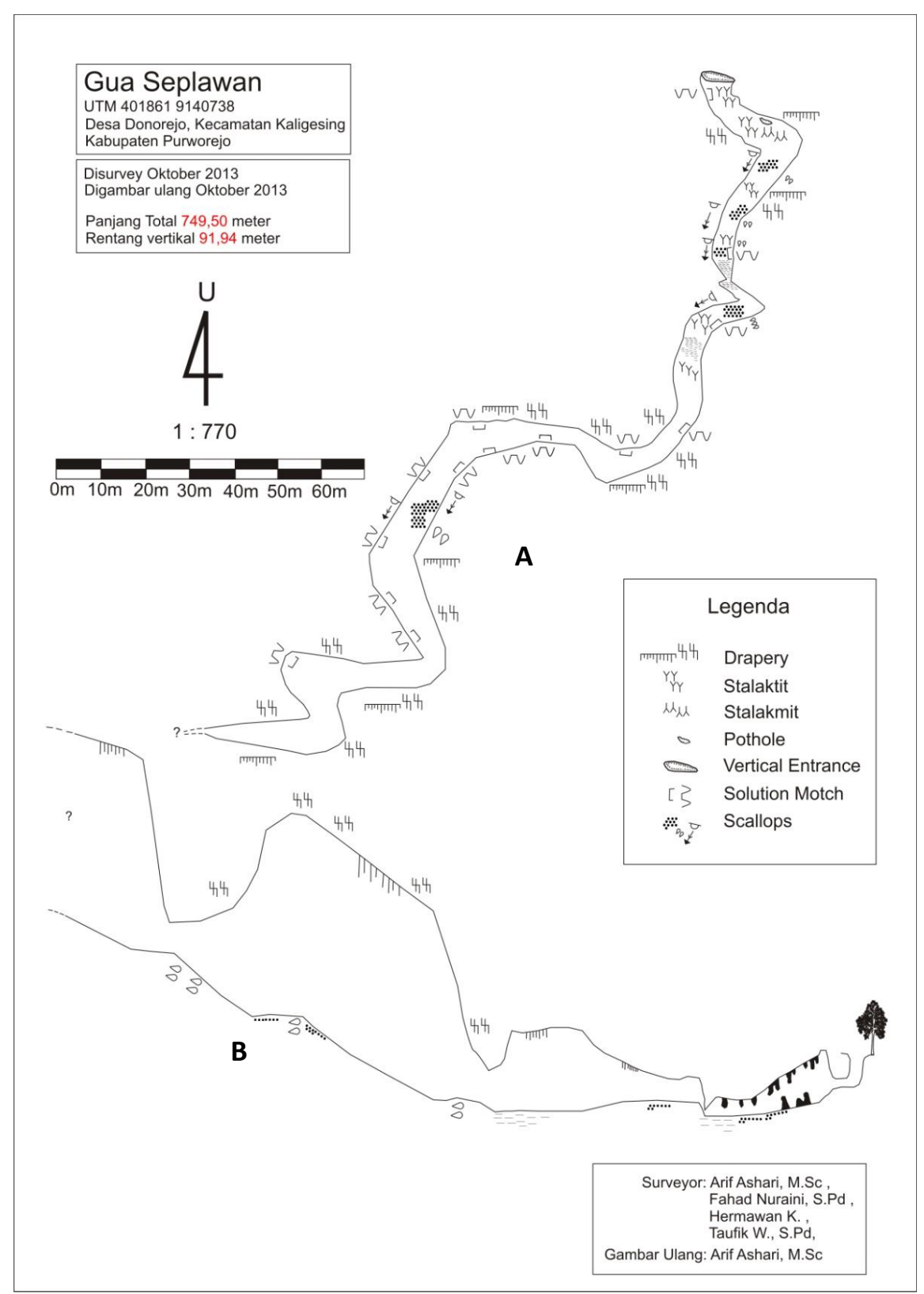

Gambar 4. Peta lorong Gua Seplawan: A. plan view, B. extended view

\section{Pembahasan}

Hasil penelitian menunjukkan Gua Seplawan termasuk gua dengan lorong utama tunggal, terbentuk oleh karena pelebaran lubang ponor di sepanjang bidang kekar batugamping yang berhubungan dengan sistem aliran bawah permukaan. Pintu masuk Gua Seplawan berbentuk vertikal terletak pada dasar cekungan tertutup (Gambar 5). Gua Seplawan memiliki tipe dan ukuran lorong yang bervariasi, bahkan di bagian akhir penelusuran dijumpai lorong berukuran besar. Beberapa saluran terhubung dengan lorong utama namun tidak dapat diakses. Menurut Palmer (1991), karakteristik gua lorong tunggal seperti yang dijumpai di Gua Seplawan merupakan perkembangan yang belum sempurna, sekalipun beberapa diantaranya berukuran 
besar. Dalam perkembangan selanjutnya tipe lorong tunggal akan berkembang menjadi branchwork, network, spongework, anastomotic, atau ramiform, tergantung lingkungan setempat. Keterangan ini diperkuat oleh pendapat Dom dan Wicks (2003) yang mencontohkan perkembangan gua-gua tunggal di Missouri menjadi bentuk yang lebih rumit terutama maze dan branchwork, pada awal perkembangannya dicirikan oleh pengikisan lantai gua oleh aliran. Proses pengikisan lantai gua pada saat ini sangat banyak dijumpai di Gua Seplawan.

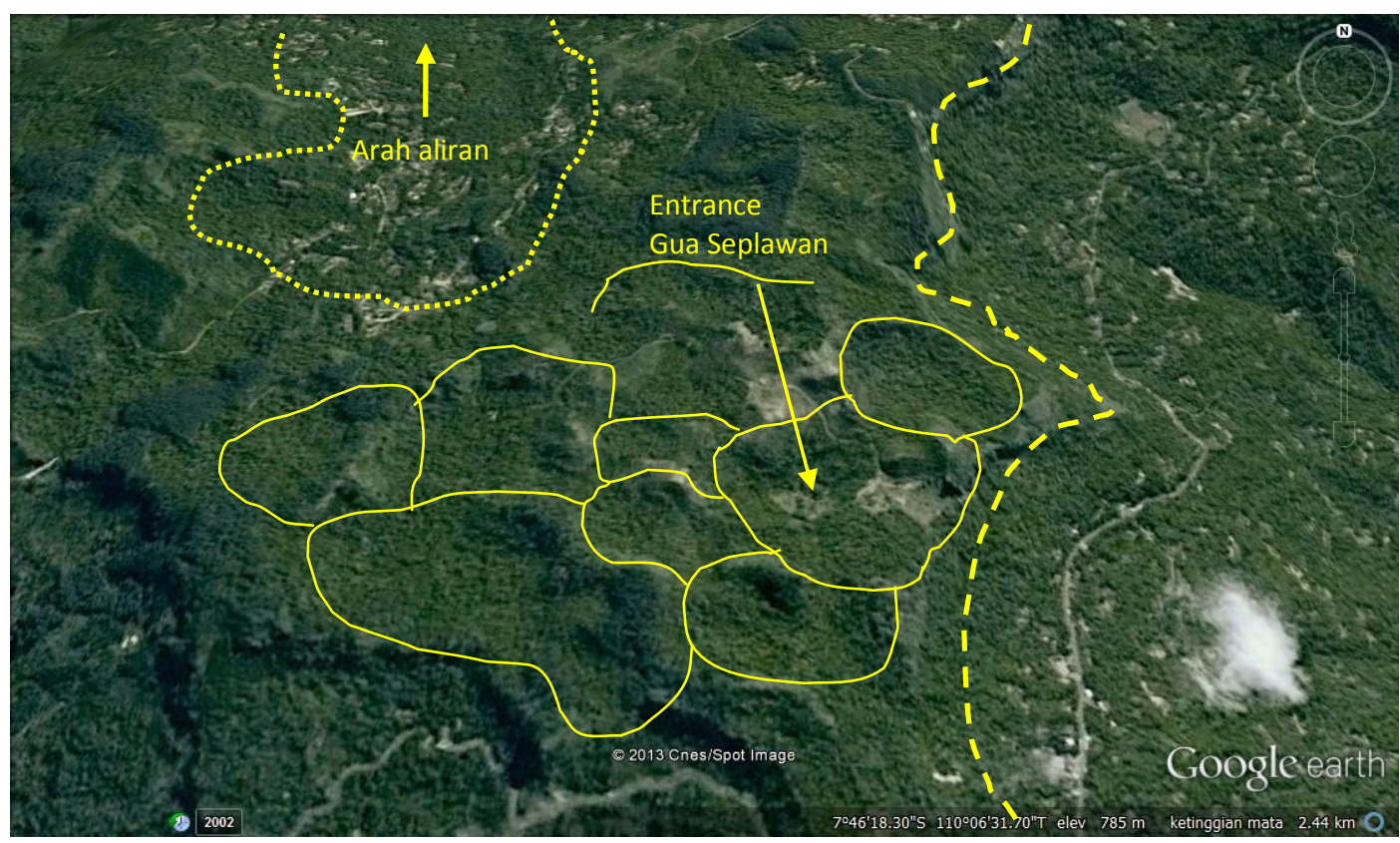

Gambar 5. Kondisi morfologi Karst Jonggrangan sekitar Gua Seplawan dilihat pada citra satelit Quickbird.

Pada gambar 5 Gua Seplawan terdiri dari dolin (garis tidak terputus), escarpment (sebagai garis putus-putus), dan lembah permukaan (titik-titik). Gua Seplawan berkembang pada dasar salah satu dolin tersebut. Gua Seplawan berbentuk pit cave, dengan ciri mulut gua vertikal atau membentuk pola bertingkat pada dinding gua (Myloire dan Carew, 1995). Pit cave sering disebut juga vadose cave karena terbentuk oleh aliran vadose. Miller (1996) menyebutnya sebagai swallet. Menurut teori vadose, perkembangan gua terjadi oleh ekskavasi aliran menuju muka air tanah bebas. Air yang berasal dari suatu input yang besar kemudian mengalir menuruni zona vadose atau tak jenuh menuju muka air tanah, yang telah terbentuk oleh beberapa proses sebelumnya pada keadaan sebelum gua itu terbentuk (Adji). Osborne (2003) secara khusus menyebut pintu masuk gua berbentuk vertikal yang terhubung dengan lorong di dasar gua sebagai surface lowering entrance, dimana penurunan permukaan medan mendesak ke kedudukan gua yang ada di bawahnya. 
Lorong-lorong kecil yang tidak dapat diakses berhubungan dengan lorong utama sebagai jalur aliran. Hal ini menunjukkan bahwa Gua Seplawan berhubungan langsung dengan sistem input air dari medan karst di atasnya. Disamping itu Gua Seplawan berada pada kedudukan yang tidak terlalu dalam di bawah permukaan. Gua dengan karakteristik semacam ini dikenal sebagai epigenic caves, dimana tenaga yang bekerja dalam perkembangan gua terutama adalah input air permukaan di sekitar gua (Palmer, 1991). Lorong-lorong aliran ini tidak dijumpai di seluruh bagian Gua Seplawan. Perkembangan conduit yang belum mendominasi seluruh lorong gua menunjukkan bahwa Gua Seplawan masih berada pada tahap transisi perkembangan dari gua terisolasi. Jenis gua terisolasi ini juga memiliki ukuran yang besar dengan diameter antara 1-100 meter dan panjangnya mencapai beberapa kilometer (Frumkin dan Fischhendler, 2005).

Tipe lorong yang dijumpai di Gua Seplawan meliputi eliptical passage, joint passage, rectangular passage, dan canyon. Perkembangan tipe-tipe lorong tersebut dipengaruhi oleh bidang perlapisan batugamping (Bogli 1980, dalam Gillieson, 1996; Lazaridis, 2006). Eliptical passage dan canyon berkembang pada bidang perlapisan batugamping yang miring. Eliptical passage berkembang tanpa pengaruh pada erosi dasar saluran, sebaliknya canyon berkembang bila dasar saluran semakin dalam sehingga terdapat struktur bertingkat pada lantai gua. Gorge shaped passage merupakan tahap awal perkembangan canyon. Rectangular passage berkembang pada bidang perlapisan batugamping mendatar, sedangkan joint passage berkembang oleh karena adanya retakan vertikal pada perlapisan batugamping. Variasi tipe lorong ini menunjukkan variasi kondisi perlapisan batugamping. Dalam perkembangan selanjutnya bentuk-bentuk lorong tersebut termodifikasi oleh proses erosi dan deposisi material dalam gua.

Solution notch merupakan bentukan speleogen yang paling umum dijumpai di Gua Seplawan. Solution notch merupakan ceruk pada dasar dinding gua yang terbentuk akibat pengikisan oleh aliran. Keberadaan solution notch mengindikasikan perkembangan Gua Seplawan berlangsung di bawah pengaruh muka air tanah karst, dan sedikit pengaruh dari aliran vadose (Gillieson, 1996). Selain solution notch, bentukan speleogen lain yang dijumpai adalah scallops, solution pockets, dan pothole. Kenampakan ini kebanyakan dijumpai di bagian awal penelusuran yaitu pada lokasi-lokasi yang sangat terpengaruh oleh aliran dalam gua. Solution pocket dapat bekembang pada lantai maupun dinding gua, namun umumnya berkembang sangat baik pada atap gua. Pembentukan solution pocket dapat berlangsung di bawah pengaruh percampuran air tawar dan air laut di daerah kepesisiran atau pengaruh aliran disertai tekanan udara pada saat terjadi banjir di dalam lorong gua (Ford dan Williams, 2007). Di Gua Seplawan, solution pocket berkembang pada dinding gua 
yang terbentuk oleh karena pengaruh aliran. Pothole merupakan cekungan-cekungan pada lantai gua yang terbentuk oleh karena erosi baik aliran maupun tetesan. Ford dan Williams (2007) secara khusus menyebutkan pothole terbentuk bila kemiringan dasar gua semakin terjal dengan batuan yang keras, yang mengacu pada pengaruh aliran. Pothole di Gua Seplawan tidak hanya dijumpai pada dasar gua yang terjal sehingga tidak menutup kemungkinan pothole terbentuk oleh pengikisan tetesan air dari atap gua atau stalaktit. Scallop merupakan bentukan cekung berukuran kecil dan dangkal yang terdapat pada lantai, atap, ataupun dinding gua. Proses pembentukan scallop hampir sama seperti solution pocket yaitu terutama akibat pengikisan oleh aliran turbulen, namun menghasilkan bentuk yang lebih teratur dengan ukuran lebih kecil (Ford dan Williams, 2007; Lazaridis, 2006). Di Gua Seplawan scallops biasanya terbentuk bersama-sama dengan solution pocket.

Runtuhan (breakdown) hampir tidak dijumpai di Gua Seplawan. Hal ini menunjukkan faktor-faktor penyebab runtuhan seperti bidang perlapisan batugamping yang diperlemah, diskontinuitas struktur, litostratigrafi, serta kondisi geohidrologi setempat belum berpengaruh secara optimum (Ford dan Williams, 2007; Klimchouk dan Andrejchouk, 200). Speleothem cukup banyak dijumpai khususnya di bagian awal penelusuran gua yang terdiri dari stalaktit, stalagmit, drappery, dan flowstone. Stalaktit di Gua Seplawan terbentuk pada lorong dengan atap gua berbentuk mendatar, sehingga tetesan air bergerak secara vertikal melalui retakan pada bidang perlapisan batugamping. Stalaktit yang terbentuk relatif pendek walaupun dalam perkembangannya tidak menutup kemungkinan dapat mencapai panjang 3 hingga 6 meter (Ford dan Williams, 2007). Drapery lebih banyak dijumpai daripada stalaktit dengan persebaran hampir merata di seluruh bagian gua. Pembentukan drappery tidak hanya terbatas pada atap gua horizontal. Ford dan Williams (2007) memberikan keterangan bahwa pembentukan drapery dan curtain dapat terjadi bila aliran keluar dari retakan batu gamping menetes pada lorong yang miring atau di bawah stalaktit yang runcing. Kondisi semacam ini tidak terlalu banyak dijumpai di Gua Seplawan.

\section{Penutup}

Kajian mengenai morfologi gua memiliki banyak manfaat. Selain memberikan informasi rekam jejak perkembangan gua terkait potensi sumberdaya dan kerentanannya terhadap kerusakan, kajian ini juga bermanfaat untuk mendukung pengembangan pariwisata penelusuran gua. Selama ini pariwisata minat khusus penelusuran gua di Indonesia tampaknya belum banyak memiliki nilai edukasi dan baru sebatas pada rekreasi. Demikian pula dengan rekreasi di Gua Seplawan yang telah dikembangkan sebagai obyek wisata namun informasi morfologinya belum 
tersampaikan dengan baik. Padahal nilai edukasi inilah yang dapat menumbuhkan rasa kecintaan pada gua dan akhirnya tumbuh sikap untuk memelihara gua dan tidak merusak/mengotori gua, sebagaimana yang biasa dilakukan oleh para peminat rekreasi gua yang meninggalkan sampah dan mencoret-coret gua. Morfologi yang terbentuk dalam gua menunjukkan karakteristik suatu kawasan karst, dan karakteristik ini memberikan petunjuk bagaimana seharusnya kawasan karst tersebut dikelola. Melalui informasi morfologi dan perkembangan gua diharapkan dapat memberikan masukan bagi pengelolaan gua yang optimum sekaligus mempertahankan kelestariannya.

\section{Daftar Pustaka}

Dom, J.E. dan Wicks, C.M. 2003. Morphology of the Caves of Missouri. Journal of Cave and Karst Studies 65 (3): 155-159

Ford, D. dan Williams, P. 2007. Karst Hydrogeology and Geomorphology. Sussex: John Wiley and Sons.

Frumkin, A. dan Fischhendler, I. 2005. Morphometry and Distribution of Isolated Caves as a Guide Phreatic and Confined Paleohydrological Conditions. Geomorphology 67: 457-471.

Gillieson, D. 1996. Cave: Processes, Development, and Management. Oxford: Blackwell Publisher

Klimchouk, A.B. dan Andrjchuk, V.N 2003. Karst Breakdown Mechanisms from Observations in the Gypsum Caves of the Western Ukraine: Implications for Subsidence Hazard Assessment. Speleogenesis and Evolution of Karst Aquifer 1 (1): 1-20.

Lazaridis, G. 2006. Almopia Speleopark (Pella, Macedonia, Greece): MorphologySpeleogenesis of The Caves. Scientific Annals, School of Geology Aristotle University of Thessaloniki (AUTH) Special Volume 98: 33-40.

Miller, T.E. 1996. Geologic And Hydrologic Controls on Karst And Cave Development in Belize. Journal of Cave and Karst Studies 58 (2): 100-120.

Osborne, R.A.L. 2003. Halls and Narrows: Network Caves in Dipping Limestoe, Example from Eastern Australia. Speleogenesis and Evolution of Karst Aquifer 1 (2): 1-14.

Palmer, A. 1991. Origin and Morphology of Limestone Caves. Geological Society of America Bulletin 103: 1-21.

Wynne, J.J. dan Pleytez W. 2005. Sensitive Ecological Areas and Species Inventory of Actun Chapat Cave, Vaca Plateau Belize. Journal of Cave and Karst Studies 67 (3): 148-157 
| Kajian Geomorfologi Kompleks Gua Seplawan Kawasan Karst Jonggrangan

I Kajian Geomorfologi Kompleks Gua Seplawan Kawasan Karst Jonggrangan 